\title{
Crafting a Culture of Connections and Collaborations
}

\author{
Barbara Atkinson
}

Executive Vice Chancellor

The University of Kansas Medical Center

\begin{abstract}
om Friedman's bestseller The World is Flat provides a clarion call to every educator and researcher in the United States to respond to a changing world order-one in which the undeniable superiority of higher education in the United States is no longer undeniable. Many are studying the swift and possibly fundamental changes coming in higher education. One author, Larry Lauer, in his 2006 book, Uncertain Times, states, "There is a different attitude toward the role of governments, who should support education, the responsibilities of students and parents, higher education as a competitive industry, and even the declining reputation of American institutions. Some would say it is an industry at risk. At minimum, it is an industry about to change - and change dramatically worldwide."
\end{abstract}

As Lauer notes, "most people agree that academic institutions are essential to the success of their individual careers. When pressed, they also recognize the role of academia in improving their overall quality of life. And most acknowledge that these institutions must be called upon to produce the resourceful and learned leaders who will solve the problems of a world in turmoil. But political leaders responsible for dealing with these conflicts are the very people who are cutting back support for the industry that must ultimately find solutions to these problems. It is a terrible irony, but it is reality nonetheless."

It is in these uncertain times that some will write yet another premature obituary for higher education. But we can also benefit from the context provided by Clark Kerr who provides hope that far from becoming relics, universities will continue to survive and perhaps even prosper in this new world order. He wrote, "About eighty-five institutions in the Western World established by 1520 still exist in recognizable forms, with similar functions and with unbroken histories, including the Catholic Church, the Parliaments of the Isle of Man, of Iceland and of Great Britain, several Swiss Cantons and seventy universities." But the fact that universities have proven both resilient and adaptable until now does not guarantee their safety in the future.

Public higher education enrolls 77\% of all students in higher education. These institutions drew about $50 \%$ of their operating support from taxpayers 
in the 1980s. Today money from the state provides about $30 \%$ of funding. At some universities, such as Virginia and Colorado state funding contributes less than $10 \%$ of operating support.

\section{Privatization in Kansas:}

We have not been immune in Kansasfrom the trends that have impacted public universities throughout the United States. State support as a proportion of the overall budget of our institution has also declined and a larger share of the cost of obtaining an advanced degree has shifted to the student and their family. In Fiscal Year 1990 the state appropriated $16.3 \%$ of its budget to fund higher education. By FY 2003 that amount had declined to $11.83 \%$.

Results of a study commissioned by Kansas Citizens for Higher Education and conducted by MGT of America concluded that Kansas public financial support for higher education has continued to decline relative to national averages, to levels that are generally lower relative to the Big 12 states than in the prior year. Faculty salaries are farther behind national average salaries for faculty in similar institutions, and farther behind average salaries in the states located around Kansas.

In fiscal year 2001 the KU Medical Center received $\$ 101$ million dollars from the state; in fiscal year 2007 that amount is now $\$ 113$ million. Figuring inflation-including significant cost increases for fixed expenses such as employee benefits and utilities-we have actually lost purchasing power during the past decade. By contrast, our tuition revenue has grown from \$11 million in Fiscal Year 2001 to nearly \$22.5 million in the current Fiscal Year.

We have had to aggressively grow non-state sources of revenue in order to maintain current levels of programming including externally funded research and clinical income. While federal support for biomedical research has grown significantly over the past decade, this growth has now plateaued and in some instances-such as funding for Title VII programs-been cut with significant consequences.

The talent of our faculty fuels the momentum we enjoy. Great students want to study with great scholars. Great scholars can demand competitive salaries, excellent space and support. Their work earns external grants and awards. The results of their research enhance the reputation of the institution and advances human health. We must compete for this talent with our peer public institutions and private universities. The competitive pressure to acquire top talent continues to create budgetary pressures for us.

\section{Challenges and Opportunities}

While privatization policies have arisen at least partially from the budget problems that states face, as well as from policymakers' willingness to shift the costs of higher education from taxpayers to students, they also arise from the view that forcing the publics to behave more like the privates and compete for resources will lead to increased efficiencies and the elimination of waste. Meanwhile, as state support becomes an increasingly smaller proportion of their budgets, many public institutions want to be freed from governmental 
constraints that lead to inefficiencies in their operations and to have the freedom to make economic decisions that will improve their ability to compete with the privates.

\section{Privatization can Work}

The separation of The University of Kansas Hospital from the university and the creation of a separate privatized state authority was the catalyst for the Hospital's renaissance. The utilization of "private" entities such as the KU Research Institute, Inc. and Kansas University Physicians, Inc., KU Health Partners, Inc. have provided the medical center with valuable tools for flexibility in resource management and for expediency in planning and managing the research and clinical enterprises.

Privatization has also grown our research infrastructure. Under legislation approved by the Kansas Legislature a new $\$ 57$ million biomedical research center was constructed on our campus. A \$19 million gift from the Hall Family Foundation and a guarantee from the state to pay the first five years of bonded indebtedness made the building and its furnishings a reality. But the financial plan for the building requires the "indirects" from grants earned by researchers in the building to pay off the remaining 15 years of debt. In essence, the building will allow us to attract and retain top scientific talent. This talent will allow us to successfully compete for research grants and awards. A portion of those grants will be dedicated to retiring the debt on the space.

The Kansas Bioscience Authority also provides a valuable tool for potential funding of university research through its statutory mission to support the development of rising scholars and eminent scientific talent in Kansas universities. The funds for these initiatives are derived from growth in the bioscience sector of the Kansas economy.

\section{Opportunities Exist to Capitalize on Privatization}

Exceptional Transfer of Wealth: Over the next 50 years, between $\$ 41$ trillion and $\$ 136$ trillion will be passed down from one generation to the next constituting the largest intergenerational transfer of wealth in American history. The opportunity to leverage this transfer of wealth to support biomedical research is strong.

Public support for biomedical research is strong. Research!America poll results indicate that $76 \%$ of Americans value research designed to improve health care and $63 \%$ are even willing to pay more taxes to support medical research; $79 \%$ support basic research as well. When asked to select national priorities, $95 \%$ of Americans selected health-related research as among their top priorities. That was tied for $5^{\text {th }}$ place with national defense, behind only education, jobs, social security/medicare, and disaster preparedness. Homeland security was ranked as a top priority by $92 \%$ but tax cuts only by $79 \%$

The community and state have embraced life sciences research as an essential economic driver-the most powerful tool available to help transform the regional economy into a knowledge-based economy capable of competing in the global economy. 


\section{Creating a Culture of Connections and Collaborations:}

To exploit these trends we must do more as leaders within our institutions to establish a culture of connections and collaborations.

First we must collaborate among ourselves - to achieve efficiencies and to maximize results. The NIH is increasingly looking for big projects to fund-projects that benefit from the insights of many researchers looking at the same problem from different perspectives. The extent to which we are capable of creating robust communities of researchers committed to networking with each other may determine our success at competing for increasingly competitive federal grants.

Next we must collaborate with others beyond our own institutions. The KU Medical Center's collaboration with the Stowers Institute is paying dividends for us-and is the single most important factor in positioning us favorably in the minds of Kansas City civic leadership.

Silos that define the academy must become more transparent and more porous. The leadership of within the university must encourage interdisciplinary collaborations and accelerate research that crosses traditional boundaries.

We must also diversify our revenue streams. This will require a greater capacity at our medical center to earn revenue from translational and clinical research including clinical trials. While most research does not "pay" there are some forms of research funded by private enterprise that can augment the research enterprise in valuable ways. We must engage knowledgeable managers to help us take better advantage of commercialization opportunities and work directly with the economic development community to be a partner whose expertise is valued and supported.

We must also engage in a more aggressive advancement strategy. If we are being privatized by state policy we must act more like private institutions in the way we cultivate connections with our alumni and in the way we raise private funds to support our mission.

-We need greater flexibility in accessing endowment funds and more staff to help cultivate gifts. We need to seek state support to match some portion of private contributions. We need to be in "campaign mode" almost continuously - at least when it comes to medical research fundraising. And we must look beyond traditional endowment constituencies - to cultivate a wide array of potential donors whose affinity to cure disease exceeds their traditional higher education loyalties.

-We must significantly expand our efforts to connect with grateful patients-and allow them to support our work as a part of their legacy.

-We must continuously and aggressively communicate the purpose of our work and its relevance to the public and encourage their participation and support. To create a sound basis for this communication we must "research" our research-and extract compelling data and results that underscore the return on investment.

- We must protect our brand and reputation-people want to connect with excellence. Any scandal or impropriety 
affects the standing of the institution and diminishes the ability to leverage the brand into private support. Core values must be articulated and the "character" of an institution must be reflected in and modeled by its leadership. There must be an authentic commitment to core values-not just lip service-if donors are to be expected to build their legacy on the platform of the institution. This may mean saying no to some gifts or programs -in order to remain true to the mission.
Reward systems must reward true performance and not just longevity. Experience in corporate and other "real world" venues must be accommodated in tenure and faculty appointment systems.

The leadership of our university - from department chair to CEO-must be change agents, prepared to embrace the possibilities of the future and skilled at making the connections and encouraging the collaborations that will fuel real results and provide real returns in this emerging era of privatized public higher education. 